\title{
Preparatory Postural Adjustments in Parkinsonian Patients with Postural Instability
}

\author{
Robert G. Lee, Ida Tonolli, Francois Viallet, Roslyn Aurenty and Jean Massion
}

\begin{abstract}
Background: Postural instability is a common problem in patients with Parkinson's disease. This paper reports results of a study undertaken to investigate some of the possible mechanisms responsible for this instability. Methods: Preparatory postural adjustments associated with a lateral leg raising task were studied in five parkinsonian patients and four age-matched controls. Recordings included ground reaction forces, kinematics, and surgace EMG activity from multiple leg muscles. Results: In normal subjects there was a well-defined sequence of events preceding the onset of leg elevation, beginning with a transfer of centre of foot pressure (CP), initially toward the moving leg and then back to the support side, followed by displacement of the trunk toward the support side. In the more severely affected parkinsonian patients, the amplitude of the the initial displacement of CP was markedly reduced. The interval between the earliest force changes and the onset of leg elevation was prolonged and the relative timing of the kenematic adjustments during this interval was disrupted. In addition the alternating burst and periods of inhibition observed in the EMG recordings from the normal subjects were replaced by continuous tonic EMG activity. Conclusions: These observations suggest that abnormalities in programming preparatory postural adjustments may contribute to postural instability in some patients with advanced Parkinson's disease.
\end{abstract}

RÉSUMÉ: Ajustements posturaux préparatoires chez les patients parkinsoniens avec instabilité posturale. Introduction: L'instabilité posturale est un problème fréquent chez les patients atteints de la maladie de Parkinson. Nous rapportons les résultats d'une étude des mécanismes qui sont possiblement responsables de cette instabilité. Méthodes: Nous avons étudié les ajustements posturaux préparatoires associés à un mouvement d'abduction de la jambe chez 5 sujets parkinsoniens et 4 contrôles appariés pour l'âge. Nous avons enregistré les forces de réaction du sol, la cinématique et l'activité EMG de surface de plusieurs muscles de la jambe. Résultats: Chez les sujets normaux, on observait une séquence bien définie d'événements précédant le début de l'élévation de la jambe, débutant par un transfert du centre de pression du pied (CP), initialement vers la jambe en mouvement, puis vers le côté de l'appui, suivi par un déplacement du tronc vers le côté de l'appui. Chez les patients plus sévèrement atteints, l'amplitude du déplacement initial du CP était diminuée de façon importante. L'intervalle entre les changements de force les plus précoces et le début de l'élévation de la jambe était prolongé et la synchronisation relative des ajustements cinématiques pendant cet intervalle était perturbée. De plus l'alternance des décharges et des périodes d'inhibition observée à l'EMG de sujets normaux était remplacée par une activité tonique continue. Conclusions: Ces observations suggèrent que les anomalies de programmation des ajustements posturaux préparatoires peuvent contribuer à l'instabilité posturale chez certains patients en phase avancée de la maladie de Parkinson.

Can. J. Neurol. Sci. 1995; 22: 126-135

The human body presents an interesting and unique set of problems from a biomechanical perspective. In the standing position a complex structure consisting of multiple linked segments must be maintained in a stable position on a relatively narrow support base formed by the feet. Almost any voluntary movement is likely to generate forces which will tend to displace the body center of gravity and produce disturbances of postural equilibrium. This is particularly true with movements of the legs which form part of the support base. To solve these problems the nervous system has evolved a number of mechanisms whereby postural adjustments are programmed to either precede or accompany voluntary movements which would otherwise perturb postural equilibrium.
Given the complexity of these mechanisms and the number of different structures involved, it is not surprising that postural instability is a relatively common problem with many disorders affecting the human central nervous system. The basal ganglia play a particularly important role in regulation of posture, ${ }^{1}$ and postural instability is a well recognized clinical problem in

From the Laboratoire de Neurobiologie et Mouvement CNRS. Marseille, France (I.T., F.V., R.A. and J.M.) and the Department of Clinical Neurosciences, University of Calgary, Calgary (R.G.L.)

RECEIVED JULY 25, 1994, ACCEPTED IN FINAL. FORM DECEMBER 19, 1994.

Reprint request to: Dr. R.G. Lee, University of Calgary. Department of Clinical Neurosciences, 3330 Hospital Drive N.W. Calgary, Alberta, Canada T2N 4N1 
many patients with Parkinson's disease. Other parkinsonian phenomena such as the freezing and festination which often occur during initiation of gait may result from disturbances in the mechanisms which normally coordinate posture and voluntary movement.

A number of different experimental approaches have been used to study these mechanisms in normal human subjects. ${ }^{2-9}$ In a recent report Mouchnino et al. ${ }^{10}$ described the ground reaction forces, kinematic events, and EMG patterns which occur in healthy young adults during a lateral leg raising task which requires a preparatory postural adjustment to preserve body equilibrium. In this paper we report our results from a set of experiments in which we used a similar task to investigate postural mechanisms in a group of parkinsonian patients and in agematched normal subjects.

\section{METHODS}

\section{Subjects}

Experiments were performed on 5 patients with Parkinson's disease (age range 61-69) and on 4 healthy volunteer subjects (age range 55-69). All of the patients and control subjects were male. Clinical details for the patients concerning the duration and severity of the disease and the treatment are provided in Table 1. Three patients showed no evidence of postural instability and were graded as stage 1 or 2 on the Hoehn and Yahr scale; ${ }^{11}$ the other two had problems with equilibrium and gait initiation and were graded as stage 4 . The parkinsonian deficits were approximately the same on the two sides in all 5 patients. All were receiving dopaminergic replacement therapy and they continued to take their medication as prescribed on the day of testing.

\section{Experimental Protocol}

From a standing position with the hands clasped in front of the body and gaze fixed straight ahead, the subjects were required to perform a lateral leg raising task in response to an auditory signal. To ensure that variations in stance width did not affect the results, markings on the force platform were used to indicate the correct initial position of the feet with the heels together and the toes pointing out such that the angle between the two feet was approximately 90 degrees. The auditory signal originated from one of two loudspeakers located on either side of the subject and the side from which the sound came indicated which leg was to be raised. Subjects were instructed to raise the leg in a lateral direction as rapidly as possible, keeping the knee fully extended, to an elevation of approximately 45 degrees and to attempt to maintain it in that position for several seconds.
Several practice trials were performed initially to allow the subjects to familiarize themselves with the task; then data were collected for four trials with each leg. To avoid anticipatory shifts in posture related to the subjects knowing in advance which leg was to be raised, the order in which the tones were presented from the two speakers was randomized.

Because two of the patients were unable to raise the leg to a full 45 degrees and performed the task much more slowly than normals, additional recordings were obtained from one of the control subjects. These consisted of one set of trials in which he was instructed to perform the leg raising task with approximately half the amplitude and velocity of the initial trials, and another set with the instruction to raise the leg very slowly (less than $25 \%$ of the initial velocity) to about one quarter of the initial 45 degree elevation.

\section{Recording Techniques}

Ground reaction forces were recorded from a Kistler force platform on which the subject stood in stocking feet. The transverse displacement of the center of foot pressure was calculated from the vertical and horizontal ground reaction forces.

Kinematic analysis was performed using a 2 camera ELITE motion analysis system ${ }^{12}$ with a sampling frequency of $100 \mathrm{~Hz}$. Twelve spherical ( $7 \mathrm{~mm}$. diameter) reflective markers were placed at the following sites on both sides of the body: over the posterolateral occiput just above the mastoid process, the posterior aspect of the acromium, the posterior superior iliac spine, the greater trochanter, the posterolateral aspect of the knee just above the head of the fibula, and the lateral malleolus of the ankle (Figure 1). The subject stood on the force platform with his back toward the cameras. The cameras were located 5 meters behind the subject and the distance between the cameras was 4 metres. Although the ELITE system reconstructs displacement of the markers in three dimensions, our analysis was limited to movement in the $X Y$ or transverse plane. The kinematic data were processed to examine displacement and velocity of displacement of individual markers and also angular changes at the hip joints.

Eight channels of EMG were recorded with pairs of surface electrodes (interelectrode distance $2 \mathrm{~cm}$ ) placed bilaterally over the gluteus medius, vastus lateralis, medial gastrocnemius, and tibialis anterior. Although most of these muscles are prime movers in the saggital plane, they do make a substantial contribution to the lateral leg raising task when it is performed with the leg externally rotated as was the case in our experiments. Other muscles such as the hip adductors and lateral flexors of the trunk, which play an important role in this task, did not generate sufficiently constant surface EMG signals to provide

Table 1: Clinical data for parkinsonian patients.

\begin{tabular}{lccccc}
\hline PATIENT & AGE & $\begin{array}{c}\text { DURATION OF } \\
\text { DISEASE (YEARS) }\end{array}$ & HOEHN-YAHR STAGE & UPDRS SCORE & $\begin{array}{c}\text { YEARS ON } \\
\text { L-DOPA THERAPY }\end{array}$ \\
P1 & & 4 & 2 & 20 & 4 \\
P2 & 66 & 4 & 1 & 6 & 3 \\
P3 & 62 & 2 & 2 & 18 & 1 \\
P4 & 65 & 16 & 4 & 34 & 15 \\
P5 & 63 & 18 & 4 & 48 & 6
\end{tabular}

*Unified Parkinson Disease Rating Scale 


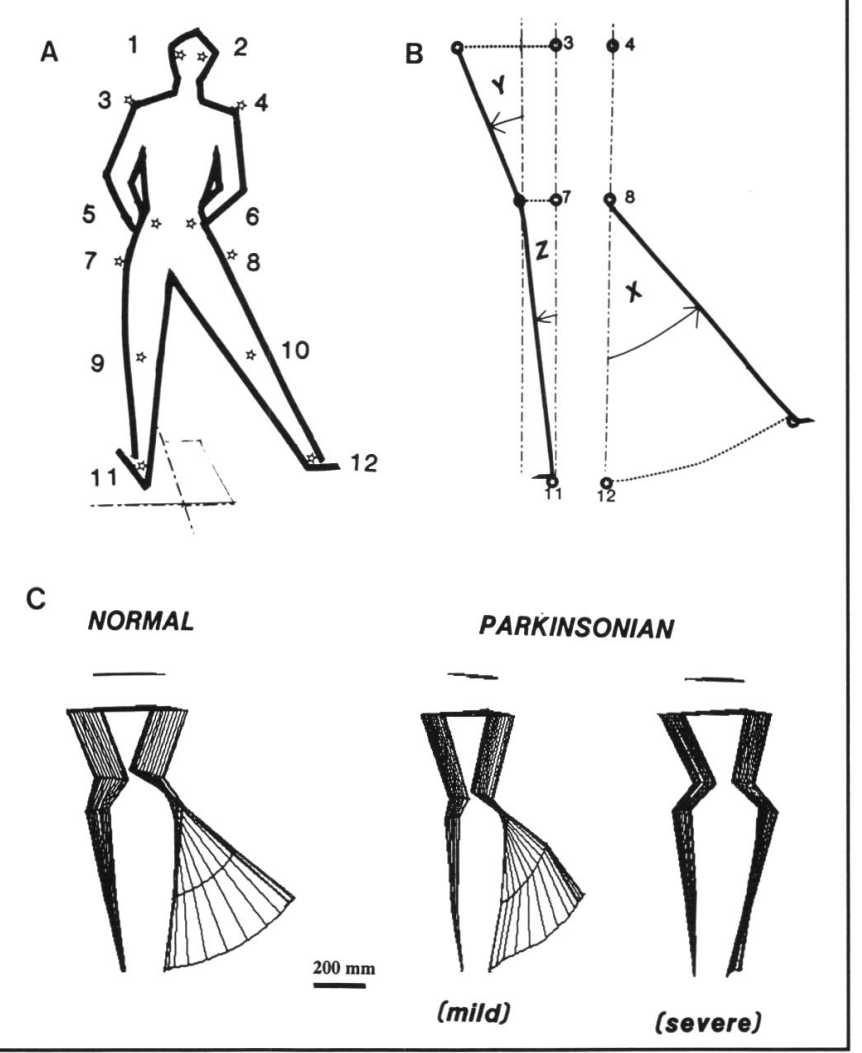

Figure 1: A) Sketch to illustrate the lateral leg raising task showing the position and numbering of the reflective markers used for kinematic analysis. B) Schematic drawing indicating angles which were measured to quantitate leg elevation and accompanying postural adjustments of the trunk. C) Stick figures illustrating kinematics for single leg raising trials in a normal subject and in 2 parkinsonian patients. Time between adjacent sticks is 50 msec.

useful information. To reduce the effect of artifact associated with movement the preamplifiers were located immediately adjacent to the electrodes. The EMG signals were amplified by a factor of 1000 , band pass filtered from $30 \mathrm{~Hz}$ to $1 \mathrm{kHz}$, and rectified. Since the higher frequency components were not essential for our analysis the EMG was digitized with a sampling frequency of $500 \mathrm{~Hz}$. Each trial included $3 \mathrm{sec}$ of recording of EMG, kinematics, and ground reaction forces following the start signal.

\section{Data Analysis}

The relative timing and amplitude of events were determined by visual inspection of data from individual trials using an interactive graphics program, and measurements were made by placing cursors on selected points. Figure 2 illustrates schematically the principal measurements which were made from the force platform data and the kinematic recordings. For the force data these measurements included the onset time for displacement of $\mathrm{CP}$, the timing and amplitude of the first peak ( $\mathrm{T} 1$ ) following onset of displacement, and the time and amplitude at the final point where the $\mathrm{CP}$ trace stabilized, or the maximum amplitude of displacement toward the support leg if no stable final position was reached. Kinematic analysis consisted of measurements of the onset time and amplitude of lateral movement of the shoulder and hip on the support side and of the ankle on the moving

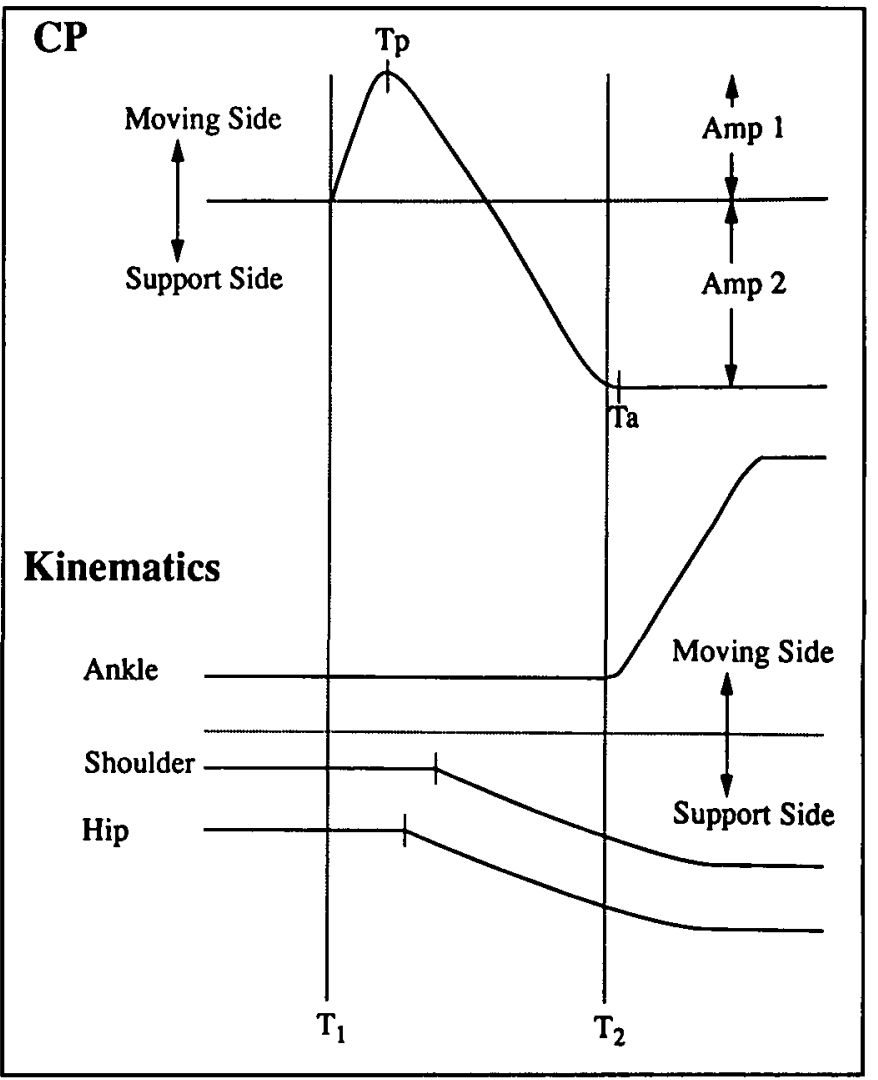

Figure 2: Schematic illustration showing principal timing and amplitude measurements made from centre of pressure tracing and from kinematic data, represented in this example by displacement of the ankle, hip, and shoulder markers in the frontal plane.

side. Measurements were also made from the records showing displacement of markers on other parts such as the head and from the velocity traces, but for simplicity these traces are not shown in the schematic illustration.

The method used for obtaining angular measurements is illustrated in Figure 1. Angle X, representing the amplitude of the leg movement, was determined by calculating the angle between the vertical and the hip-ankle segment of the moving leg. The inclination of the trunk and the supporting leg toward the support side were indicated by angles $\mathrm{Y}$ and $\mathrm{Z}$ respectively, obtained by calculating the angles respectively formed between the vertical and the shoulder-hip segment and between the vertical and the hip-ankle segment. Angular velocities were obtained by differentiating the angle-time signals.

Statistical analysis was performed using the Student $t$ test to compare mean values obtained by averaging measurements from individual trials in each subject.

\section{Results}

To maintain whole body equilibrium during the task performed by our subjects, the leg raising movement must be preceded by a displacement of the body center of gravity toward the supporting leg. As illustrated schematically in Figure 2 there is a coordinated posturo-kinetic sequence of events beginning with a shift of the center of pressure (CP) on the force platform followed by displacement of the trunk toward the supporting 
side and finally by elevation of the moving leg. This sequence can be considered as two components - an initial postural adjustment phase beginning with the first change in the $C P$ record, and a movement phase commencing at the onset of leg elevation. One of the advantages of the lateral leg raising task used in this experiment is that the kinematic and kinetic changes during these two phases occur in a single plane, the frontal plane. To identify possible abnormalities in the parkinsonian patients the two components of the task will be analysed successively.

\section{Postural Adjustment Phase}

This component is defined as the interval between the onset of $\mathrm{CP}$ displacement (time $\mathrm{TI}$ ) and the onset of leg elevation (time T2). Changes occurring during this phase can be quantified by examining the force platform data and the kinematic recordings.

\section{CP Displacement}

The CP was first displaced laterally toward the leg which was going to move with the maximum excursion in that direction occurring at time $\mathrm{Tp}$ indicated in figure 2 . This was followed by transfer of the CP in the opposite direction toward the supporting leg until it reached a new stable position at time Ta. The initial displacement of the CP was accompanied by a horizontal transversal reaction force directed toward the supporting foot (see Figure 3). These events reflect the acceleration of the center of body mass toward the supporting side. The transfer of body weight on to the supporting foot terminates after the CP curve has reached its new stable position.

Examples of the CP records and the corresponding horizontal forces for a normal subject and for two parkinsonian patients are shown in Figure 3. In the normal subject the CP trace reached an early peak (Tp) in the direction of the moving leg and then moved rapidly toward the supporting leg. In most trials the discrete new equilibrium point where the $C P$ trace stabilized (Ta) occurred quasi simultaneously with the onset of leg raising, although there were some subsequent oscillations as the subject attempted to maintain equilibrium with the leg elevated. Table 2 lists mean values for amplitude and duration of these two phases in the CP displacement ending respectively at $\mathrm{Tp}$ and $\mathrm{Ta}$, and for the velocity of the transfer phase (from $\mathrm{Tp}$ to $\mathrm{Ta}$ ). Results are pooled for all the normal subjects at the normal speed and amplitude of leg raising.

The five parkinsonian patients showed large interindividual variability which correlated with the wide range of clinical disability. In the three less severely affected patients without evidence of postural instability (PI, P2, P3) the amplitude of the initial CP displacement at time $\mathrm{Tp}$ was either in the normal range (P1, P3) or increased (P2), and the duration of this phase was normal. The subsequent transfer phase of the $\mathrm{CP}$ record form $\mathrm{Tp}$ to Ta was similar to the normal pattern except for subject $P 2$ who showed a marked increase in amplitude and velocity of this phase.

In the two more severely affected patients (P4, P5) the major abnormalities were a marked reduction in the amplitude of the $\mathrm{CP}$ displacement toward the moving leg and considerable slowing of the subsequent transfer phase. In most trials for these subjects the $\mathrm{CP}$ record never reached a point of stabilization and it was usually not possible to identify a precise time Ta representing the end of the transfer phase. It was, however, still possible to identify in each trial a point where maximum amplitude of displacement toward the support side occurred, and this was used for measurement of Amp2 (Figure 2 and Table 2).

Despite the relative brevity of the postural adjustment phase in subjects $\mathrm{P} 1, \mathrm{P} 2$, and $\mathrm{P} 3$, these subjects had more difficulty than normals maintaining equilibrium during this task. They often stumbled or were unable to keep the leg elevated for the full duration of the trial. It seemed as if the initial postural adjustment phase of the task was performed without accompanying planning for final stabilization.

\section{Kinematic Changes Associated With Body Weight Transfer}

Figure 4 shows examples of the time course of kinematic changes for single trials from one normal subject and three parkinsonian patients. Transfer of body weight toward the supporting leg was reflected by lateral displacement of the trunk

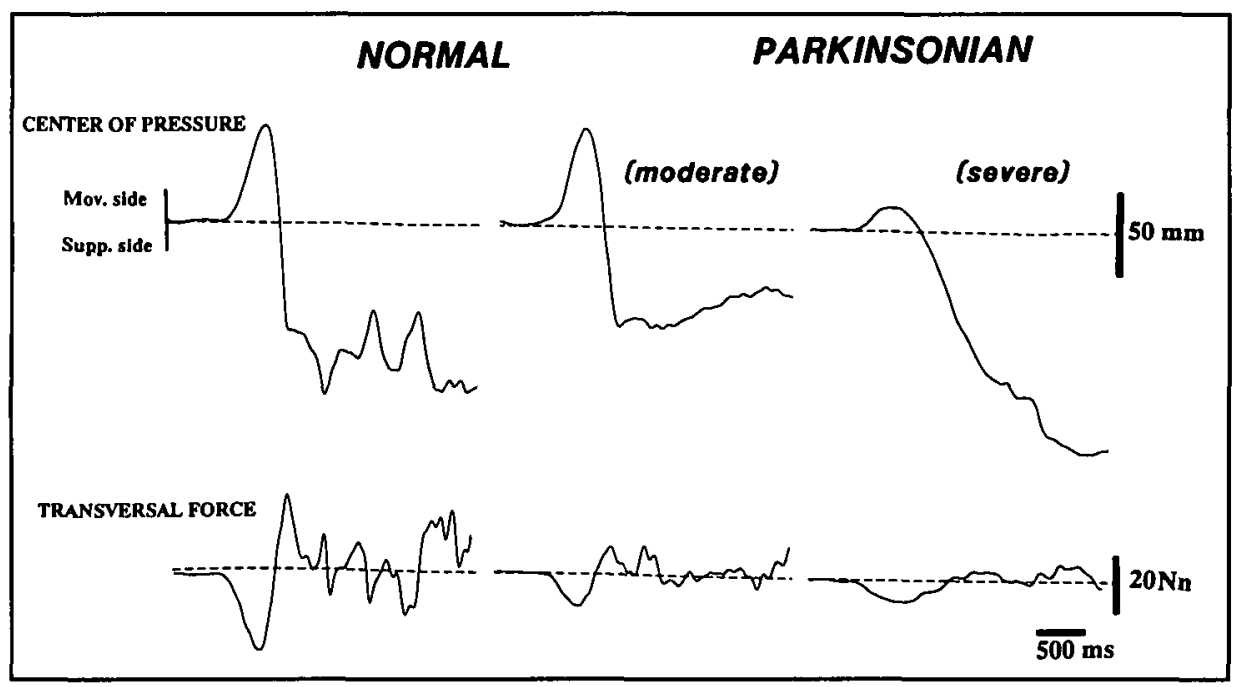

Figure 3: Representative force-plate recordings from a normal subject and from 2 parkinsonian patients. Upper traces show displacement of centre of foot pressure $(C P)$ in the transverse direction with upward deflection indicating displacement toward the side of the moving foot. Lower traces represent horizontal forces. Downward deflection indicates a reaction force toward the support side. 
Table 2: Amplitude and timing of changes in center of foot pressure on force plate. Values represent means with standard deviations in brackets. Number of trials is shown at top of each column. N4-50\% and N4-25\% refer to the trials by subject N4 at reduced speed and amplitude.

\begin{tabular}{|c|c|c|c|c|c|c|c|c|}
\hline & $\begin{array}{c}\text { Normals } \\
(n=31)\end{array}$ & $\begin{array}{c}\text { N4-50\% } \\
(\mathrm{n}=8)\end{array}$ & $\begin{array}{c}\mathbf{N} 4-25 \% \\
(n=7)\end{array}$ & $\begin{array}{c}\text { P1 } \\
(\mathbf{n}=7)\end{array}$ & $\begin{array}{c}\text { P2 } \\
(\mathrm{n}=7)\end{array}$ & $\begin{array}{c}\text { P3 } \\
(\mathbf{n}=\mathbf{8})\end{array}$ & $\begin{array}{c}P 4 \\
(n=5)\end{array}$ & $\begin{array}{c}\text { P5 } \\
(\mathbf{n}=7)\end{array}$ \\
\hline $\begin{array}{l}\text { Amplitude of initial peak } \\
\text { (amp } 1 \cdot \mathbf{m m} \text { ) }\end{array}$ & $\begin{array}{c}52.4 \\
(22.4)\end{array}$ & $\begin{array}{l}19 \\
(5.4)\end{array}$ & $\begin{array}{l}29 \\
(14.2)\end{array}$ & $\begin{array}{l}48.0 \\
(3.9)\end{array}$ & $\begin{array}{c}98.1 \\
(12.2)\end{array}$ & $\begin{array}{l}62.9 \\
(4.5)\end{array}$ & $\begin{array}{l}14.8 \\
(4.4)\end{array}$ & $\begin{array}{l}14.0 \\
(2.2)\end{array}$ \\
\hline $\begin{array}{l}\text { Time of initial peak } \\
\text { (T1-Tp, mm) }\end{array}$ & $\begin{array}{l}363 \\
(90)\end{array}$ & $\begin{array}{l}320 \\
(74.6)\end{array}$ & $\begin{array}{l}300 \\
(66.0)\end{array}$ & $\begin{array}{l}288 \\
(26)\end{array}$ & $\begin{array}{l}279 \\
(80)\end{array}$ & $\begin{array}{l}265 \\
(26)\end{array}$ & $\begin{array}{l}327 \\
(74)\end{array}$ & $\begin{array}{l}320 \\
(91)\end{array}$ \\
\hline $\begin{array}{l}\text { Maximum amplitude of displacement } \\
\text { toward support side (amp 2-mm) }\end{array}$ & $\begin{array}{c}70.6 \\
(22.3)\end{array}$ & $\begin{array}{l}55 \\
(10.8)\end{array}$ & $\begin{array}{l}68 \\
(21.5)\end{array}$ & $\begin{array}{l}73.9 \\
(5.8)\end{array}$ & $\begin{array}{c}85.1 \\
(14.2)\end{array}$ & $\begin{array}{c}84.5 \\
(20.5)\end{array}$ & $\begin{array}{c}88.8 \\
(25.8)\end{array}$ & $\begin{array}{c}63.7 \\
(23.5)\end{array}$ \\
\hline $\begin{array}{l}\text { Time for Transfer } \\
\text { (Tp-Ta, msec) }\end{array}$ & $\begin{array}{c}374 \\
(167)\end{array}$ & $\begin{array}{l}1162 \\
(488)\end{array}$ & $\begin{array}{c}831 \\
(170)\end{array}$ & $\begin{array}{l}356 \\
(47)\end{array}$ & $\begin{array}{l}214 \\
(31)\end{array}$ & $\begin{array}{c}316 \\
(105)\end{array}$ & * & $*$ \\
\hline $\begin{array}{l}\text { Peak velocity of transfer } \\
\text { (between Tp and Ta } \mathrm{mm} / \mathrm{msec} \text { ) }\end{array}$ & $\begin{array}{c}466.7 \\
(192.7)\end{array}$ & $\begin{array}{l}190 \\
(53.6)\end{array}$ & $\begin{array}{l}226 \\
(73.4)\end{array}$ & $\begin{array}{l}347.1 \\
(66.0)\end{array}$ & $\begin{array}{l}808.6 \\
(96.1)\end{array}$ & $\begin{array}{l}534.9 \\
(65.9)\end{array}$ & $\begin{array}{l}141.2 \\
(77.4)\end{array}$ & $\begin{array}{c}70.1 \\
(20.8)\end{array}$ \\
\hline
\end{tabular}

*A precise point Ta at which final postural stabilization was achieved could not be identified in the majority of trials for subjects P4 and P5. Peak velocity of transfer for these subjects was calculated between $\mathrm{Tp}$ and the point of maximum displacement toward the support side, wherever it occurred.

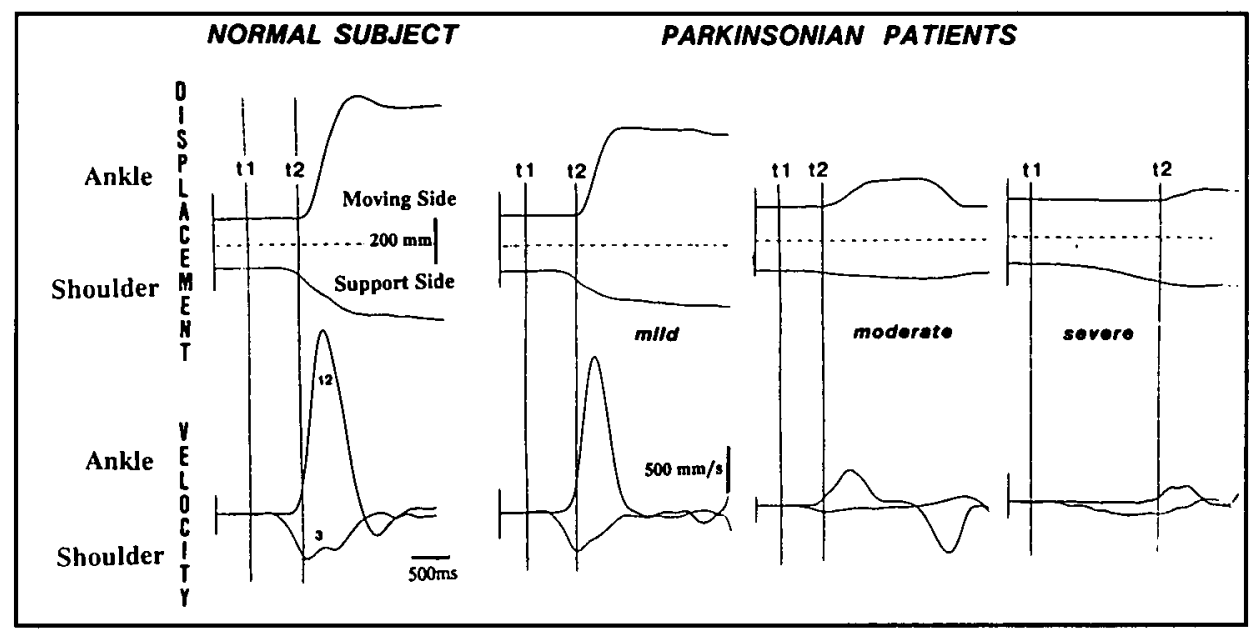

Figure 4: Time course for amplitude and velocity of displacement of ankle marker on moving leg and shoulder marker on support side for individual trials in 1 normal subject and 3 parkinsonian patients.

markers at the shoulder and hip level in a direction opposite to that of the moving leg. To simplify the figure hip kinematics are not illustrated in Figure 4. Table 3 lists mean values for the onset times of shoulder and hip displacement together with the amplitude of displacement at these sites at the onset of lateral leg raising (time T2). This table also includes data for the amplitude and velocity of leg elevation during the movement phase. Note that these values are given as angular changes for angle $\mathrm{X}$ (see Figure 1).

To examine the sequential order of the CP changes and the kinematic events during the postural adjustment phase we have rearranged the timing measurements to indicate the points at which events occur prior to time T2, the onset of leg elevation. These measurements are presented graphically in
Figure 5. The mean time for the T1-T2 interval in normal subjects was $609 \mathrm{msec}$. For parkinsonian subjects P1, P2, and P3 this interval was similar to the normals. In fact subject P2 who was a very fit and athletic individual despite his Parkinson's disease had a shorter T1-T2 interval than the majority of normal subjects. However, for subjects P4 and P5 the mean T1T2 interval was markedly prolonged $-973 \mathrm{msec}$ and 1760 msec respectively.

In the normal subjects the mean onset time for hip displacement occurred $32 \mathrm{msec}$ before onset of shoulder displacement. Because of the large variability between individual trials this difference was not statistically significant, but it did suggest a tendency for a bottom to top sequence in the organization of lateral body displacement during the postural adjustment phase. 
Displacement at both the hip and shoulder started before the early peak (Tp) of the $\mathrm{CP}$ record which corresponded to the onset of body weight transfer toward the supporting leg.

In the parkinsonian patients the sequence of the postural adjustment events was disrupted in the majority of trials with the initial trunk displacement toward the supporting leg occurring at the shoulder rather than at the hip level. This top to bottom organization was observed in all patients except P3 in whom onset of movement at the hip and shoulder was nearly simultaneous. In the more severely affected patients P4 and P5 the onset of trunk displacement was delayed and did not occur until after the initial peak $\mathrm{Tp}$ in the CP record. A similar pattern was noted in patient $P 1$, but the other less severely affected patients (P2 and P3) showed a similar sequence to that of normals with lateral trunk displacement beginning before time $\mathrm{Tp}$. All but one of the parkinsonian patients showed a marked reduction in the amplitude of lateral trunk displacement, measured at the hip, at the onset of leg raising at time T2 (see Table 3).

\section{Movement Phase}

This component begins with the onset of the leg raising movement at time $\mathrm{T} 2$ and continues until the final position is attained with the leg elevated to approximately 45 degrees. To analyse the kinematics of this movement we measured displacement of the marker on the lateral malleolus and also the magnitude and velocity of changes in angle $X$ (see Figure 1). Values for the angular measurements are summarized in Table 3. In normal subjects the mean peak angular velocity for angle $X$ was $112 \pm 28$ degrees and this occurred at a mean time of 889 $\pm 164 \mathrm{msec}$ after $\mathrm{T} 1$. In the 3 mildly affected patients movement amplitude indicated by angle $X$ was within the normal range. In the 2 more severely affected patients the amplitude and velocity of leg movement was markedly reduced and one of them (P5) could barely lift his foot above the ground during some trials.

The maximum angular excursions for the three angles defined in Figure 1 are presented in Figure 6. The maximum value for angle $X$ was approximately 40 degrees for the normal subjects and for the three mildly affected patients. For patients P4 and P5 the mean value for angle $X$ was less than 10 degrees. During leg elevation displacement of the trunk in the opposite direction continues until the leg reaches its final position. Angle $Z$ which represents lateral rotation about the ankle joint of the supporting leg was similar in all normal subjects and in all the parkinsonian patients. In the normal subjects and in patients $\mathrm{P} 1$ and $\mathrm{P} 2$ the maximum value obtained for angle $\mathrm{Y}$ was greater than that for angle $\mathrm{Z}$ indicating that, at the final position, there was additional inclination of the trunk toward the supporting side beyond the axis provided by rotation about the ankle. In patients P3, P4, and P5 the final values for angles $Y$ and $Z$ were almost equal indicating that there was no additional inclination of the trunk as part of the postural adjustment.

\section{Effect of Reduced Amplitude and Velocity of Leg Movement}

It is possible that the changes in the sequence of kinematic events observed in subjects P4 and P5 were simply due to the

Table 3: Kinematic measurements. Timing of events indicates the time after $\mathrm{Tl}$, the initial change in $\mathrm{CP}$ on the force plate (see Figure 2).

\begin{tabular}{ccccccccc}
\hline & $\begin{array}{c}\text { Normals } \\
(\mathrm{n}=31)\end{array}$ & $\begin{array}{c}\text { N4-50\% } \\
(\mathrm{n}=8)\end{array}$ & $\begin{array}{c}\text { N4-25\% } \\
(\mathrm{n}=7)\end{array}$ & $\begin{array}{c}\text { P1 } \\
(\mathrm{n}=7)\end{array}$ & $\begin{array}{c}\text { P2 } \\
(\mathrm{n}=7)\end{array}$ & $\begin{array}{c}\text { P3 } \\
(\mathrm{n}=8)\end{array}$ & $\begin{array}{c}\text { P4 } \\
(\mathrm{n}=5)\end{array}$ & $\begin{array}{c}\text { P5 } \\
(\mathrm{n}=7)\end{array}$ \\
\hline
\end{tabular}

\section{POSTURAL ADJUSTMENT PHASE}

\begin{tabular}{|c|c|c|c|c|c|c|c|c|}
\hline $\begin{array}{l}\text { Onset time for shoulder } \\
\text { displacement (msec.) }\end{array}$ & $\begin{array}{c}274 \\
(67.4)\end{array}$ & $\begin{array}{c}255 \\
(84.9)\end{array}$ & $\begin{array}{c}269 \\
(88.2)\end{array}$ & $\begin{array}{c}263 \\
(122)\end{array}$ & $\begin{array}{c}223 \\
(48.6)\end{array}$ & $\begin{array}{c}230 \\
(59.2)\end{array}$ & $\begin{array}{c}350 \\
(119)\end{array}$ & $\begin{array}{l}370 \\
(96)\end{array}$ \\
\hline $\begin{array}{l}\text { Amplitude of shoulder } \\
\text { displacement at time } \mathrm{T} 2(\mathrm{~mm})\end{array}$ & $\begin{array}{c}39 \\
(13.6)\end{array}$ & $\begin{array}{l}40.6 \\
(9.4)\end{array}$ & $\begin{array}{l}61.2 \\
(18)\end{array}$ & $\begin{array}{c}42 \\
(11.1)\end{array}$ & $\begin{array}{l}21.6 \\
(8.3)\end{array}$ & $\begin{array}{c}7.3 \\
(1.8)\end{array}$ & $\begin{array}{c}38.8 \\
(23.8)\end{array}$ & $\begin{array}{r}20.3 \\
(9.8)\end{array}$ \\
\hline $\begin{array}{l}\text { Onset time for hip } \\
\text { displacement (msec.) }\end{array}$ & $\begin{array}{c}242 \\
(65.9)\end{array}$ & $\begin{array}{c}231 \\
(88.5)\end{array}$ & $\begin{array}{c}251 \\
(107)\end{array}$ & $\begin{array}{l}326 \\
(84)\end{array}$ & $\begin{array}{l}258 \\
(59)\end{array}$ & $\begin{array}{l}221 \\
(27)\end{array}$ & $\begin{array}{c}390 \\
(114)\end{array}$ & $\begin{array}{l}467 \\
(86)\end{array}$ \\
\hline $\begin{array}{l}\text { Amplitude of hip displacement } \\
\text { at time } \mathrm{T} 2(\mathrm{~mm})\end{array}$ & $\begin{array}{c}24.2 \\
(15.8)\end{array}$ & $\begin{array}{l}25.3 \\
(7.2)\end{array}$ & $\begin{array}{c}41.3 \\
(10.1)\end{array}$ & $\begin{array}{l}17.7 \\
(8.9)\end{array}$ & $\begin{array}{c}7.9 \\
(4.3)\end{array}$ & $\begin{array}{c}5.4 \\
(1.8)\end{array}$ & $\begin{array}{c}28.6 \\
(18.2)\end{array}$ & $\begin{array}{l}13.1 \\
(6.5)\end{array}$ \\
\hline
\end{tabular}

\section{MOVEMENT PHASE}

\begin{tabular}{|c|c|c|c|c|c|c|c|c|}
\hline $\begin{array}{l}\text { Onset time for ankle displacement } \\
\text { (T1-T2 msec.) }\end{array}$ & $\begin{array}{c}609 \\
(140)\end{array}$ & $\begin{array}{c}750 \\
(114)\end{array}$ & $\begin{array}{l}1111 \\
(193)\end{array}$ & $\begin{array}{c}585 \\
(44.8)\end{array}$ & $\begin{array}{c}374 \\
(43.4)\end{array}$ & $\begin{array}{c}477 \\
(45.1)\end{array}$ & $\begin{array}{c}973 \\
(185)\end{array}$ & $\begin{array}{l}1760 \\
(563)\end{array}$ \\
\hline Maximum amplitude for angle $X\left(^{\circ}\right)$ & $\begin{array}{l}43.5 \\
(8.7)\end{array}$ & $\begin{array}{c}33.6 \\
(2)\end{array}$ & $\begin{array}{l}22.4 \\
(4.5)\end{array}$ & $\begin{array}{l}39.2 \\
(4.8)\end{array}$ & $\begin{array}{l}38.7 \\
(4.2)\end{array}$ & $\begin{array}{l}40.8 \\
(5.5)\end{array}$ & $\begin{array}{c}7.6 \\
(7.8)\end{array}$ & $\begin{array}{l}3.3 \\
(0.9)\end{array}$ \\
\hline Peak velocity of angle $X\left({ }^{\circ} / s\right)$ & $\begin{array}{l}112.4 \\
(28.1)\end{array}$ & $\begin{array}{l}47.9 \\
(5.8)\end{array}$ & $\begin{array}{r}26.4 \\
(4.9)\end{array}$ & $\begin{array}{c}91.8 \\
(13.9)\end{array}$ & $\begin{array}{c}98.8 \\
(10.7)\end{array}$ & $\begin{array}{c}89 \\
(17)\end{array}$ & $\begin{array}{c}19 \\
(21)\end{array}$ & $\begin{array}{c}6 \\
(1.3)\end{array}$ \\
\hline
\end{tabular}




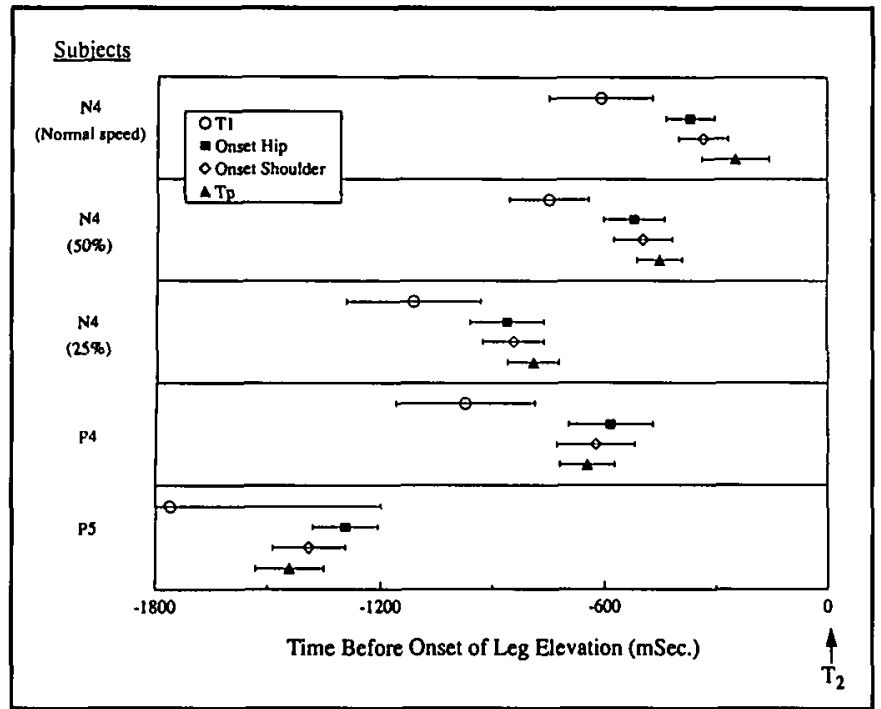

Figure 5: Relative timing of events occurring before time T2, the onset of displacement of the ankle marker on the moving leg. TI represents time of initial displacement in $\mathrm{CP}$ recording; $T$ p the time of peak displacement of CP toward moving leg (see Figure 2). Values shown are means, error bars represent l SD. Results for all 4 normal subjects have been pooled.

fact that these subjects performed the task much more slowly and that the amplitude of leg elevation was less than in the normal subjects. For this reason additional recordings were obtained from normal subject $\mathrm{N} 4$ - one set of trials in which the subject was instructed to perform the task at approximately $50 \%$ of the usual speed, and a second set of very slow trials at about $25 \%$ normal speed with a reduced amplitude of leg elevation. The relative timing of events preceding $\mathrm{T} 2$ for these experiments is presented in Figure 7 together with the results from parkinsonian subjects P4 and P5 using the same format as in Figure 5. In the normal subject, as the velocity of the movement becomes less, there is a progressive increase in the length of the T1-T2 interval, and for the very slow trials the mean value for this interval is similar to what was obtained in subject P4. However, the timing of the onset of displacement of the trunk toward the support side in relation to $\mathrm{Tl}$ remains fairly constant as the $\mathrm{Tl}$ $\mathrm{T} 2$ interval increases. For subject $\mathrm{P} 4$ the mean interval from $\mathrm{T} 1$ to onset of trunk displacement was prolonged in comparison to the slow trials for subject N4 with a comparable T1-T2 interval. Furthermore, the sequence of kinematic events with hip displacement occurring before shoulder displacement was preserved during the slow trials in the normal subject. Therefore, the reversal in this sequence observed in subjects P4 and P5 would not seem to be explained simply by a reduced velocity of movement, and may reflect a more fundamental disturbance in the programming of postural adjustments in the more severely affected parkinsonian subjects.

Measurements of the force changes and the kinematic events associated with the slow trials in subject N4 are included in Tables 2 and 3. The amplitude of the initial thrust in the $\mathrm{CP}$ record and the velocity of transfer of $\mathrm{CP}$ toward the support side were reduced in comparison to the mean values for normal subjects performing the task at the usual speed, but still remained larger than the corresponding values for parkinsonian subjects P4 and P5.

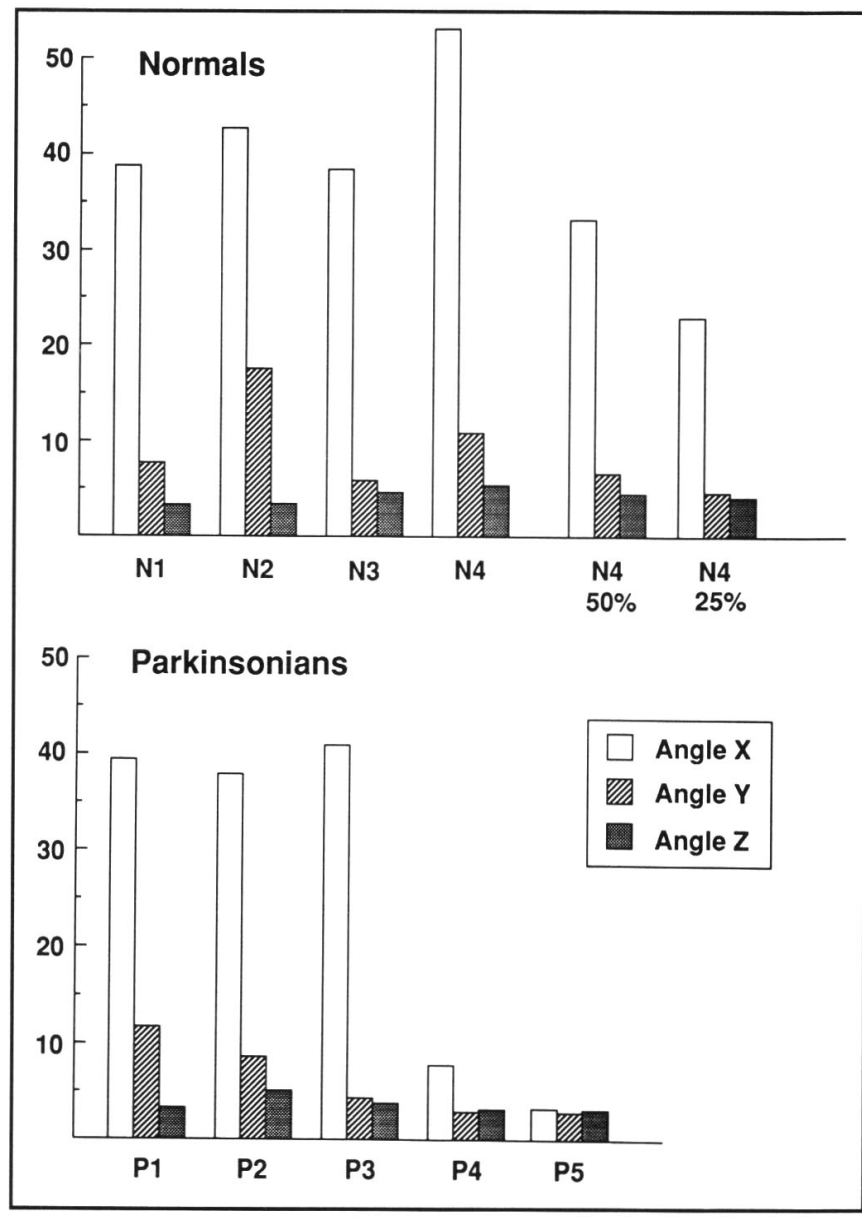

Figure 6: Mean maximum angular excursions for angles $X, Y$, and $Z$, as defined in Figure 1 for 4 normal subjects and 5 parkinsonian patients. N4-50\% and N4-25\% refer to the trials performed at reduced velocity and amplitude by normal subject $\mathrm{N} 4$.

\section{EMG Observations}

Since there was considerable variability in the EMG patterns for individual trials the main features will be described here in a qualitative manner rather than presenting a detailed analysis of amplitude and timing measurements. In the normal subjects the medial gastrocnemius (MG) of both legs was usually tonically active during the waiting period prior to the onset of the task. A constant feature in all the normal subjects was a prominent burst in the MG of the leg on the moving side occurring within the T1-T2 time window (Figure 8 ). This was often preceded by a brief period of inhibition of the tonic activity in the same muscle starting just before time T1. The MG in the leg on the support side showed a period of inhibition during the T1-T2 interval at the same time as the burst in the moving leg. This reciprocal pattern of activation-inhibition in the MG muscles on the two sides would appear to be closely associated with the force changes observed in the $\mathrm{CP}$ recording.

Immediately preceding the onset of leg elevation at time $\mathrm{T} 2$ there were EMG bursts in the gluteus medius of the support side and in the tibialis anterior (TA) of the moving leg. Patterns of activation in other muscles examined such as the vastus lateralis were less consistent. The EMG patterns in the MG and TA 


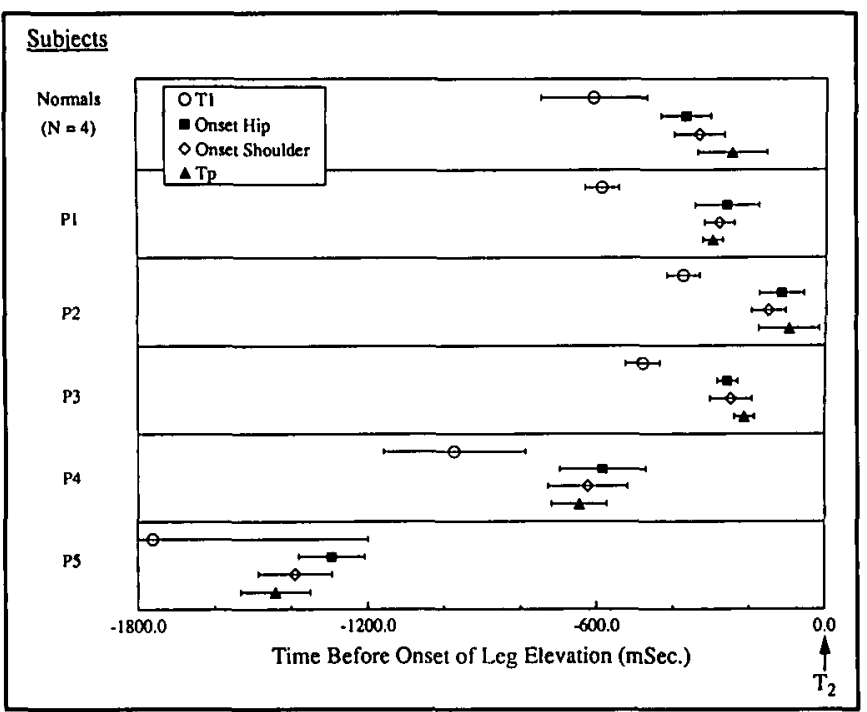

Figure 7: Relative timing of events preceding $T_{2}$ in the 2 most severely affected parkinsonian patients and in 1 normal subject performing the leg raising task at normal speed and at 50\% and $25 \%$ of normal speed. Symbols and format are the same as in Figure 5.

muscles during the slower movements performed by subject $\mathrm{N} 4$ were similar to those recorded during the usual task.

The more mildly affected parkinsonian subjects - P1, P2, and P3 - showed EMG patterns similar to those described above. However, in patients P4 and P5 the pattern was quite different. In almost all trials there was continuous activity throughout the task in all muscles examined. There was no evidence of any inhibition of this activity in the MG muscles around time $\mathrm{Tl}$, and the EMG burst in MG of the moving leg, which was a constant feature in all the normal subjects, was either completely absent or just detectable. Figure 8 shows an example from one trial for P5 to illustrate these changes.

\section{Discussion}

This study showed several abnormalities indicating a disturbance in parkinsonian patients in the sequence of events leading to elevation of one leg. The force recordings indicated that in the more severely affected patients the amplitude of the initial displacement of the center of foot pressure toward the moving side was markedly reduced and the speed at which the center of pressure (CP) was transferred back toward the support side was very slow in comparison to normal subjects. The time interval between $\mathrm{T} 1$ - the onset of displacement of $\mathrm{CP}-$ and $\mathrm{T} 2$ - the onset of leg elevation - was prolonged, and the relative timing of other kinematic events occurring within this time interval was disrupted. In addition the amplitude of displacement of the head and trunk toward the support side was reduced and the phasic bursts and periods of inhibition seen in the EMG of normal subjects performing this task were either absent or less clearly defined. It is noteworthy that these changes were most evident in the two patients who were most severely affected clinically and were beginning to show evidence of postural instability in addition to other features of Parkinson's disease. However, even though the kinetic and kinematic measurements in the less severely affected patients were similar to normals, they did show evidence of an early disturbance of postural mechanisms in that they had difficulty maintaining a final stable position with the leg elevated.

There are several possible interpretations for our observations. The abnormalities noted during the postural adjustment phase in the two more severely affected patients could represent a failure in programming preparatory postural adjustments, but impairment in the movement execution sequence or in posturokinetic coordination could be contributing factors as well. With the relatively small number of subjects examined in this study, our data are not sufficient to make a clear distinction between these possibilities.

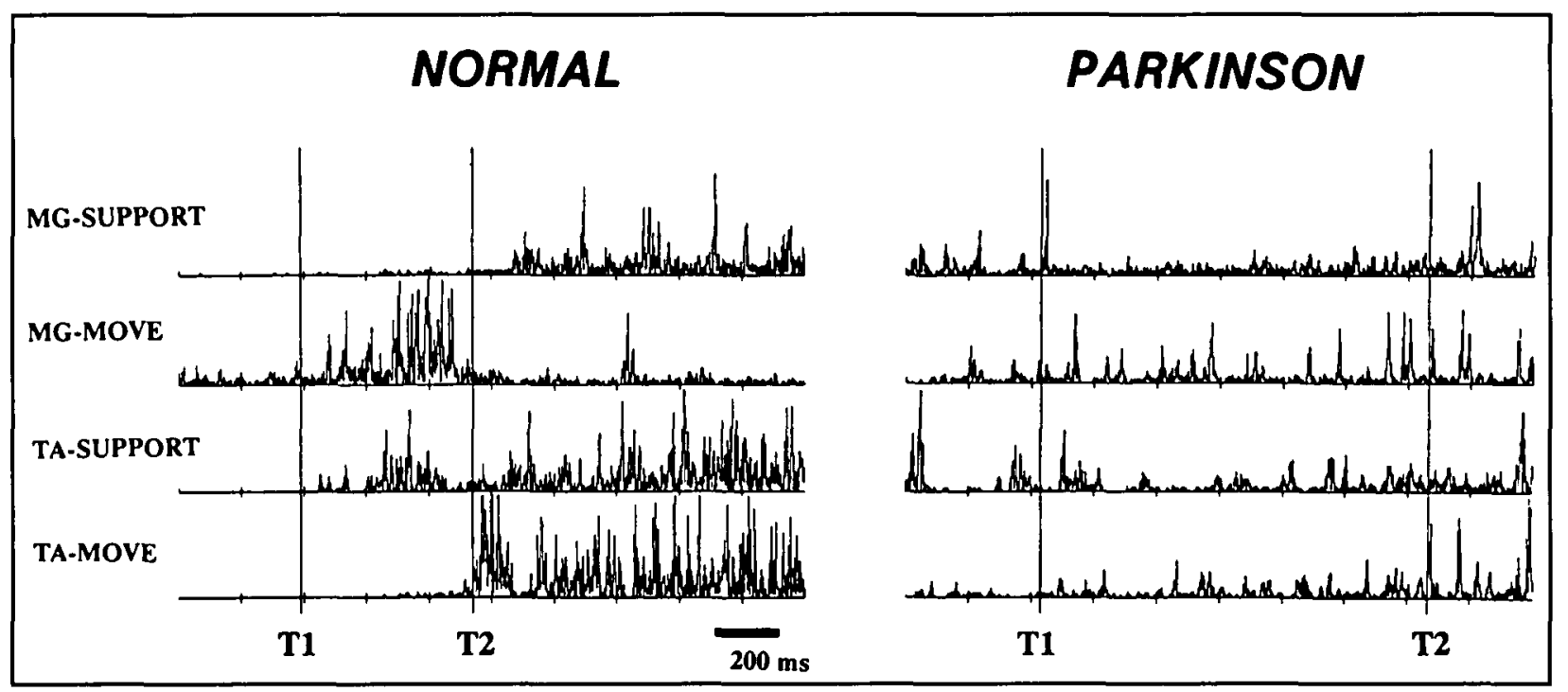

Figure 8: EMG recordings from medial gastrocnemius $(M G)$ and tibialis anterior (TA) for single trials in a normal subject and in 1 of the severely affected patients (P5). TI indicates the time of onset of CP changes, $T 2$ the onset of lateral leg elevation. 


\section{Anticipatory Postural Adjustments}

A large number of motor acts which comprise the human movement repertoire cause potential displacements of the body center of gravity (CG) and require coordination between postural mechanisms and voluntary movement to maintain equilibrium. This subject has been the topic of a recent extensive review. ${ }^{13}$ Examples of motor tasks which fall into this category include activation of posterior trunk and leg muscles when the arms are raised in front of the body or when a weight is added to the arms $\mathrm{s}^{4.58 .14}$ and the kinematic adjustments which occur during forward or backward axial movements of the trunk. ${ }^{6}$

The task used in our study is a sequential motor act which requires a particular type of preparatory postural adjustment since the moving limb forms part of the support base. Before the leg can be raised the body CG must be transferred over the supporting leg. There is evidence that in at least some normal subjects this is accomplished by feedforward mechanisms. Mouchnino et al. ${ }^{10}$ used the same motor task to compare a group of trained dancers with naive normal subjects. They observed that the dancers used a different motor strategy in which the transfer of CG and CP occurred in a ballistic manner without subsequent adjustments. Also dancers employed what was described as an translation strategy which resulted in the trunk remaining vertical in contrast to naive subjects who shifted their CG by inclining the entire body toward the support side. It was suggested that, presumably as a result of lengthy training, skilled dancers develop a new motor program which allows them to perform this type of task in a manner which more effectively preserves equilibrium.

Similar postural adjustments have been described by Rogers and $\mathrm{Pa}^{15}$ in normal subjects performing a hip flexion movement to raise one leg while they are in a standing position. These authors, like Mouchnino et al., observed that the transfer of the CG over the supporting leg was initiated by a thrust from the leg which was going to be elevated. This was reflected by an initial dispacement of the CP toward the moving side. A marked reduction in this initial $\mathrm{CP}$ displacement was one of the most obvious abnormalities in the more severely affected parkinsonian patients in our study.

There is evidence that postural adjustments associated with movements of the upper extremities may also be disrupted in Parkinson's disease. For example, abnormalities in the timing or amplitude of anticipatory postural adjustments which occur when rapid voluntary arm movements are made in the standing position have been reported in parkinsonian subjects ${ }^{1.6-18}$ Viallet et al. ${ }^{19}$ described abnormalities in coordination between posture and voluntary movement in a bimanual load lifting task where a weight was removed from the subject's hand either by the experimenter or by the subject himself using the other hand. With self unloading normal subjects were able to suppress activity in the tonically active muscles in the arm which was holding the load and thus prevent the arm from swinging upward. Parkinsonian patients seemed unable to program this type of feedforward adjustment. In a subsequent study ${ }^{20}$ similar abnormalities were documented in patients with lesions of the supplementary motor area (SMA), an observation which would be compatible with the concept that the SMA, which is one of the major cortical targets for the output from the basal ganglia, is concerned with programming certain types of voluntary movements.

\section{Motor Planning and Sequencing in Parkinson's Disease}

Failure to program anticipatory or preparatory postural adjustments may be part of a more general deficit in planning or programming voluntary movements in Parkinson's disease. Benecke et al. ${ }^{21}$ tested a group of parkinsonian patients using a complex motor task requiring simultaneous programming of two different motor acts with the upper extremity. They observed that the patients had considerable difficulty performing the two tasks together, whereas either task could be performed independently with relatively little difficulty. Similarly, Harrington and Haaland ${ }^{22}$ have reported that parkinsonian patients have problems generating complex sequences of hand postures. The movements are performed more slowly than in normal subjects and the patients have difficulty switching from one posture to another.

Another possible example of abnormal programming or sequencing of postural adjustments in Parkinson's disease is difficulty with initiation of gait, a common problem in many patients with more advanced disease. In normal subjects gait initiation involves a sequence of biomechanical, kinematic, and EMG events which are similar in some respects to the sequence which occurs with the lateral leg raising task. The earliest change is seen in the EMG recordings where the soleus muscles, which are tonically active during quiet standing, show a sudden period of inhibition bilaterally. ${ }^{23}$ This is followed by a dispacement of the center of foot pressure in the force recording, initially backwards and toward the side of the swing leg, and then forwards in the direction of gait initiation. As a result the $C G$ is displaced anteriorly and the whole body begins to fall forward, providing the forward momentum which is required before taking the first step. The initial backward displacement in the CP record could be considered analagous to the initial displacement of the $\mathrm{CP}$ toward the moving side in the lateral leg raising task used in our experiment.

Crenna et al. ${ }^{24}$ have studied gait initiation in parkinsonian patients and have observed that there is a failure to produce the initial inhibition of the tonic activity in the soleus muscles, and as a result, the critical initial backward displacement of the CP either fails to occur or is markedly reduced.

\section{Relationship to Postural Instability}

Numerous studies have looked at postural mechanisms in Parkinson's disease in an attempt to understand the postural instability which is such a common problem in the more advanced forms of the disease. Martin' carried out extensive studies on tilting reactions in patients. with post-encephalitic parkinsonism and concluded that postural reflexes were deficient in these patients. More recent investigations have demonstrated various abnormalities in the EMG responses to platform perturbations in parkinsonian patients. ${ }^{25.29}$ All of these results point to a deficit in the feedback responses to external postural perturbations.

A deficit in the programming of feedforward postural adjustments which occur as part of the preparation for a voluntary motor act which is going to produce a potential disturbance of body equilibrium could be one of the factors responsible for postural instability in Parkinson's disease. There is no doubt that the preparatory postural adjustment is essential for the motor act 
of lateral leg raising. If a normal subject attempts to perform this task with the support side of the body positioned close to a wall to prevent displacement of the trunk toward the support side it is impossible for him to raise the leg. Unlike patients with cerebellar ataxia, parkinsonian patients have relatively good stability when they are standing still in one position. It is primarily when they attempt to move that the dysequilibrium becomes evident, and falling during initiation of gait is common. The studies of Crenna et al. provide evidence to suggest that this may be due to failure to coordinate the preparatory postural adjustment with the other components of the motor act of gait initiation.

The question remains as to why these mechanisms should be disrupted as a result of basal ganglia disease. Discussion on this point is limited by our still incomplete understanding of the role of the basal ganglia in normal motor function. However, the recent studies of Mink and Thach ${ }^{30}$ shed some light on this area. They performed a series of experiments on monkeys trained to perform various motor tasks and examined the effects of temporary neurochemical lesions of the globus pallidus intended to interrupt the major outflow from the basal ganglia. They concluded with a hypothesis proposing that one of the roles of the basal ganglia is "to switch off the maintained motor activities, possibly including normal postural mechanisms, that would otherwise interfere with voluntary movement commands". A further extension of this hypothesis was that "basal ganglia inhibition may be a general mechanism not only for switching off one activity to allow another to operate unopposed, but also for combining in appropriate blends the activities of coactive motor programs". While these hypotheses still require further testing, they provide an attractive framework for interpretation of some of the observations from our experiment. The persistence of tonic EMG activity in the parkinsonian patients during attempts to elevate the leg and the failure to generate the sequences of inhibition and EMG bursts seen in normal subjects would be consistent with the ideas put forward by Mink and Thach.

\section{ACKNOWLEDGEMENTS}

The authors thank Jean-Claude Fabre, Annie Obadia, and Michele Coulmance for valuable technical assistance and advice.

This work was supported in part by a CNRS visiting scientist award to R.G. Lee.

\section{REFERENCES}

1. Martin JP. The Basal Ganglia and Posture. London: Pitman, 1957.

2. Cordo PJ, Nashner LM. Properties of postural adjustments associated with rapid arm movements. J Neurophysiol 1982; 47:287-302.

3. Horak FB, Esselman PE, Anderson ME, Lynch MK. The effects of movement velocity, mass displaced and task certainty on associated postural adjustments made by normal and hemiplegic individuals. J Neurol Neurosurg Psychiatry 1984; 47: $1020-1028$.

4. Friedli WG, Hallett M, Simon SR. Postural adjustments associated with rapid voluntary arm movements. I Electromyographic data. J Neurol Neurosurg Psychiatry 1984; 47: 611-622.

5. Friedli WG, Cohen L, Hallett $M$ et al. Postural adjustments associated with rapid voluntary arm movements. II Biomechanical analysis. J Neurol Neurosurg Psychiatry 1988; 51: 232-243.

6. Crenna P, Frigo C, Massion J, Pedotti A. Forward and backward axial synergies in man. Exp Brain Res 1987; 65: 538-548.

7. Bouisset $S$ and Zattara $M$. Postural muscular activities and intentional movements. Med Sport Sci 1987; 26: 735-742.
8. Zattara M, Bouisset S. Posturo-kinetic organization during the early phase of voluntary upper limb movement. I. Normal subjects. J Neurol Neurosurg Psychiatry 1988; 51: 956-965.

9. Moore SP, Rushner DS, Windus SL, Nashner LM. Human automatic postural response: response to horizontal perturbation of stance in multiple directions. Exp Brain Res 1988; 73: 648-658.

10. Mouchnino L, Aurenty R, Massion J, Pedotti A. Coordination between equilibrium and head-trunk orientation during leg movement: a new strategy built up by training. J Neurophysiol 1992; 67: 1587-1598.

11. Hoehn MM, Yahr MD. Parkinsonism: onset, progression, and mortality. Neurology 1967; 17: 427-442.

12. Ferrigno F, Pedotti A. ELITE: A digital dedicated hardware system for movement analysis via real-time TV signal processing. IEEE Trans Biomed Eng 1985; 32: 943-950.

13. Massion J. Movement, posture and equilibrium: interaction and coordination. Prog Neurobiol 1992; 38: 35-56.

14. Traub MM, Rothwell JC, Marsden CD. Anticipatory postural reflexes in Parkinson's disease and other akinetic-rigid syndromes and in cerebellar ataxia. Brain 1980; 103:393-412.

15. Rogers MW, Pai YC. Dynamic transitions in stance support accompanying leg flexion movements in man. Exp Brain Res 1990; 81: 398-402.

16. Dick JP, Rothwell JC, Berardelli A, et al. Associated postural adjustments in Parkinson's disease. J Neurol Neurosurg Psychiatry 1986; 49: 1378-1385.

17. Bazalgette $\mathrm{D}$, Zattara $\mathrm{M}$, Bathien $\mathrm{N}$ et al. Postural adjustments associated with rapid voluntary arm movements in patients with Parkinson's disease. In: Yahr, MD Bergman, KJ, eds. Advances in Neurology, Vol. 45. New York: Raven Press, 1986: 371-374.

18. Rogers MW, Kukulka CG, Soderberg GL. Postural adjustments preceding rapid arm movements in parkinsonian subjects. Neurosci Lett 1987; 75: 246-251.

19. Viallet F, Massion J, Massarino R, Khalil R. Performance of a bimanual load-lifting task by Parkinsonian patients. J Neurol Neurosurg Psychiatry 1987; 50: 1274-1283.

20. Viallet F, Massion J, Massarino R, Khalil R. Coordination between posture and movement in a bimanual load lifting task - putative role of a medial frontal region including the supplementary motor area. Exp Brain Res 1992; 88: 674-684.

21. Benecke R, Rothwell JC, Dyck JP, et al. Performance of simultaneous movements in patients with Parkinson's disease. Brain 1986; 109: 739-757.

22. Harrington DL, Haaland DY. Sequencing in Parkinson's disease: abnormalities in programming and controlling movement. Brain 1991; 114: 99-115.

23. Breniere $\mathrm{Y}$, Do MC. When and how does steady state gait movement induced from upright posture begin? J Biomech 1986; 12: 1035-1040.

24. Crenna P, Frigo C, Giovannini P, Piccolo I. The initiation of gait in Parkinson's disease. In: Berardelli A, et al., eds. Motor Disturbances II. London: Academic Press, 1990; 161-173.

25. Dietz V, Berger W, Horstmann G. Posture in parkinson's disease: impairment of reflexes and programming. Ann Neurol 1988: 24: 660-669.

26. Diener HC, Dichgans J, Guschlbauer B, et al. Associated postural adjustments with body movements in normal subjects and patients with parkinsonism and cerebellar disease. Rev Neurol (Paris) 1990; 146: 555-563.

27. Schieppati M, Nardone A. Free and supported stance in Parkinson's disease. Brain 1991; 114: 1227-1244.

28. Beckley DJ, Bloem BR, van Dijk JG, Roos RAC, Remler MP. Electrophysiological correlates of postural instability in Parkinson's disease. Electroencephalogr Clin Neurophysiol 1991; 81: 263-268.

29. Horak FB, Nutt JG, Nashner LM. Postural inflexibility in parkinsonian subjects. J Neurol Sci 1992; $111: 46-58$.

30. Mink JW, Thach T. Basal ganglia motor control: III. Pallidal ablation: Normal reaction time, muscle contraction, and slow movement. J Neurophysiol 1991; 65: 330-35I. 